\title{
MUDANÇAS NA DINÂMICA COMERCIAL DA PRODUÇÃO AGRÍCOLA DE SÃO JOÃO DA PONTA (PA)
}

\author{
Walter Luiz Jardim Rodrigues ${ }^{1}$ \\ Viviane Corrêa Santos ${ }^{2}$
}

RESUMO: Este artigo analisa as transformações ocorridas na dinâmica comercial da produção agrícola do atual município de São João da Ponta, nordeste do Pará. A partir da memória local dos moradores mais idosos, objetiva-se uma análise comparativa entre a produção e a distribuição dos produtos agrícolas da atualidade com as do passado. A rodovia PA-375, que a partir da década de 50, ligou a vila São João da Ponta (hoje atual sede municipal) a PA-136, e esta, a BR-316, alterou significantemente a forma de escoamento da produção agrícola da citada vila e das comunidades ao entorno. Portanto, busca-se analisar e representar cartograficamente a antiga dinâmica comercial dos produtos agrícolas da vila de São João da Ponta a partir da memória local dos moradores mais idosos até a atual dinâmica comercial dos produtos agrícolas do município de São João da Ponta evidenciando as profundas mudanças ocorridas tanto na dinâmica espacial desses produtos quanto na transformação socioeconômica.

\section{INTRODUÇÃO:}

O município paraense de São João da Ponta foi criado em 1995, a partir do desmembrado do município de São Caetano de Odivelas e conta com aproximadamente 5.265 mil habitantes, segundo dados do Instituto Brasileiro de Geografia e Estatística - IBGE, 2010, no entanto, como vila, o município existe há mais de 100 anos conforme observou Rodrigues; Fernandes; Pimentel (2012, p.2).

O município de São João da Ponta está localizado na mesorregião do nordeste paraense e microrregião do salgado, abrangendo uma área territorial de $196,9 \mathrm{~km}^{2}$, distante $120 \mathrm{~km}$ em linha reta da cidade de Belém. O município tem localização central na latitude $00^{\circ} 50^{\prime} 59$ 'sul e longitude $47^{\circ} 55^{\prime}$ ' 2 '’'oeste, com altitude de 34 metros em relação ao nível do mar. Limita-se ao norte e oeste com o município de São Caetano de Odivelas, ao sul com os municípios de

\footnotetext{
${ }^{1}$ wljrodrigues@gmail.com

2 correasantosv@gmail.com
} 
Terra Alta e São Caetano de Odivelas, e a leste com os municípios de Terra Alta e Curuçá. Seu principal acesso se dá pela rodovia PA-136 (Rodovia Castanhal - Curuçá) e PA-375. Possui clima equatorial quente e úmido, característico da região (RODRIGUES, 2013, p.25). A população de São João da Ponta está concentrada em sua maior parte na área rural, e isso se observa nos dados do último censo realizado em que tínhamos um total de 500 endereços urbanos contra 1.652 de endereços rurais do total de 2.522 dos endereços do município, segundo dados do IBGE, 2010.

Sendo que a parte urbana corresponde à Sede do município de mesmo nome. Não é por acaso que a maior parte da renda dos moradores do município vem da Reserva Extrativa Marinha de São João da Ponta, criada por meio do Decreto S/N de 13 de dezembro de 2002, abrangendo uma área de aproximadamente 3203,24 ha e um perímetro aproximado de cento e trinta e um mil, duzentos e sessenta e oito metros e oitenta e oito centímetros.

Possuindo na sua dominialidade territorial, a predominância do ecossistema de manguezal. Este ecossistema, segundo a Lei 4.771/65 (Código Florestal), representa áreas de preservação permanente (APP), não edificante. As comunidades usuárias moram no entorno, nas áreas de terra firme. Para essas comunidades, a unidade de conservação representa uma grande área de produção. No total são 18 comunidades que fazem parte da RESEX, divididas em 5 pólos. (ICMBIO, 2010 apud RODRIGUES; FERNANDES, 2011).

Durante seu processo histórico, a configuração espacial passou por profundas mudanças. Tais mudanças se deram de maneira mais significativas a partir da década de 50, quando a estrada PA 375 ligou a vila São João da Ponta, atual sede municipal, a PA 136 e esta a BR 316, mudando completamente a forma de escoamento da produção agrícola da citada vila e das comunidades ao entorno.

Neste trabalho, em um primeiro momento, será abordada a dinâmica comercial dos principais produtos agrícolas exportados a partir do porto da antiga vila de São João da Ponta para os principais pontos comerciais do estado, chegando, inclusive, a alcançar o exterior através de canoas a vela; em um segundo momento, será apresentada a atual dinâmica comercial dos principais produtos agrícolas exportados a partir da rodovia PA-375 alcançando, principalmente, os municípios de entorno e a capital Belém.

Busca-se, desse modo, contribuir com o avanço dos estudos sócio espaciais, utilizando-se dos recursos metodológicos da História Oral somadas às abordagens culturais da Geografia, que vem buscando novas alternativas de apreensão do espaço geográfico, e a aplicação do geoprocessamento, pois sendo o mesmo uma técnica transdisciplinar, diversas são as ciências que se beneficiam de seu uso através dos trabalhos de localização dos fenômenos e equacionamento e esclarecimento das condições espaciais (RODRIGUES, 2013). 
Figura 1 - Mapa de localização de São João da Ponta - PA.

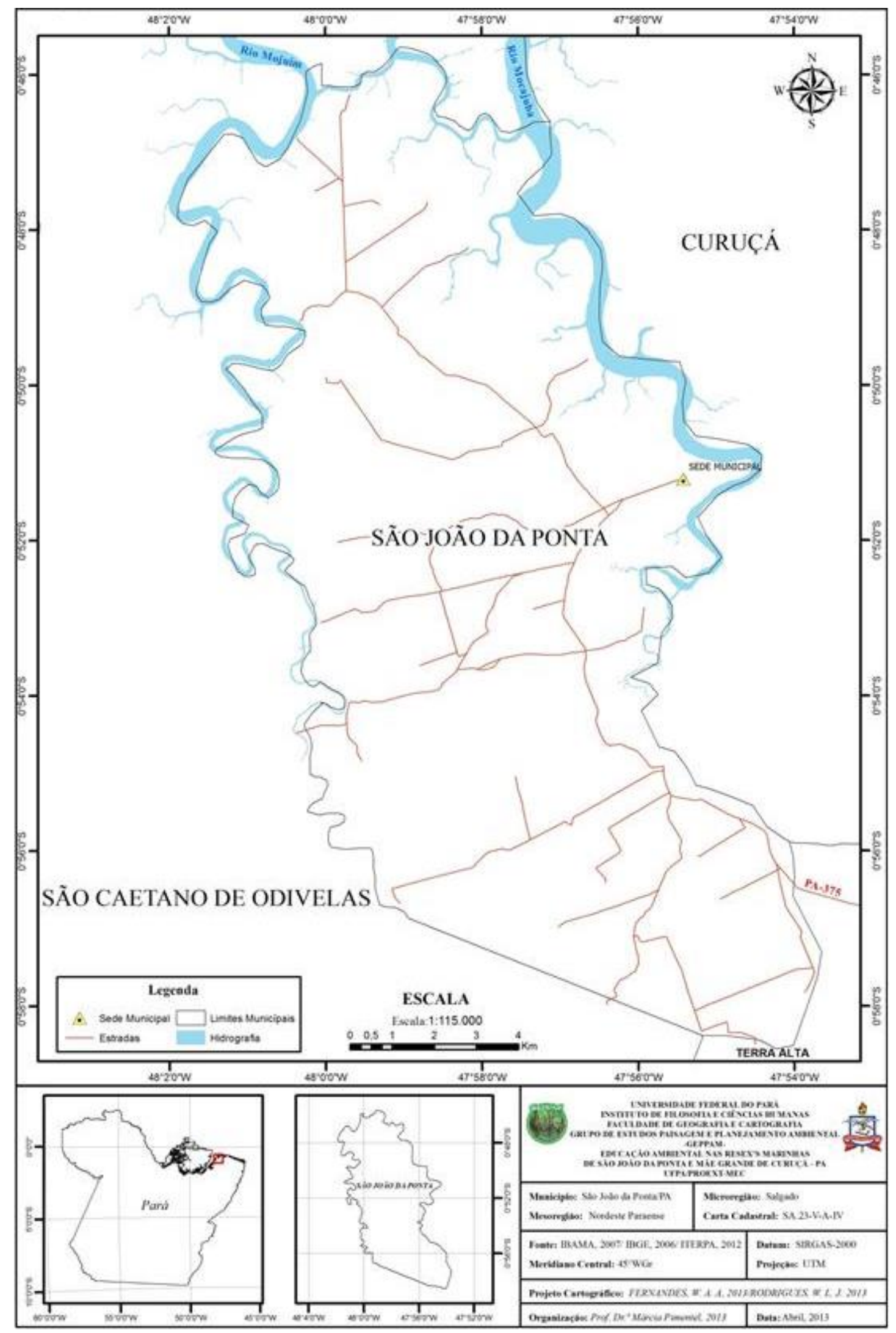

Fonte: RODRIGUES, 2003. 


\section{OBJETIVO}

Com este, objetiva-se um comparativo entre as dinâmicas espaciais dos produtos agrícolas a partir da memória local dos moradores mais idosos até os dias atuais evidenciando as profundas mudanças ocorridas tanto na dinâmica espacial desses produtos quanto na transformação socioeconômicas decorrentes.

\section{METODOLOGIA DE TRABALHO}

Para o presente estudo, foram utilizados recursos metodológicos da História Oral, uma vez que através das entrevistas gravadas em campo fora possível construir a cartografia da dinâmica comercial do passado, muito viva nas memórias dos moradores que vivenciaram sua época. Desse modo, foram desenvolvidas representações cartográficas a partir do uso das Geotecnologias, que evidenciou a área de estudo, a produção agrícola e a dinâmica comercial local antes da abertura da Rodovia PA375 na década de 50 e as mudanças decorrentes da implantação da mesma no contexto socioeconômico; posteriormente foram feitos levantamentos bibliográficos que desse suporte ao aporte teórica dessa análise ambiental, bem como, da história de ocupação de São João da Ponta. Finalizando com a produção de materiais cartográficos para espacializar os principais fluxos de mercadorias e pessoas anteriores a década de 50 e os principais fluxos de mercadorias e pessoas posteriores a década citada.

A construção da base de dados referente à memória local dos moradores mais idosos foram pautadas em trabalhos de campo, onde foram gravadas entrevistas com os moradores mais idosos do local, em especial, antigos pescadores, comerciantes, agricultores, entre outros.

Assim, foi possível uma análise das mudanças ocorridas no decorrer do tempo quanto ao uso das terras correspondente ao atual município, além de revelar a configuração espacial desses espaços agrícolas e suas consequentes dinâmicas comerciais.

\section{PRESSUPOSTOS TEÓRICOS}

Tendo em vista que parte das análises dessa pesquisa parte da percepção dos moradores é que se releva o entendimento acerca da percepção ambiental, em que o sentido expressivo é a visão. A teoria de Gebson dá suas contribuições para facilitar a compreensão acerca da percepção visual do espaço e do meio ambiente, pois este se utiliza da interpretação do meio 
ambiente com as categorias psicológicas do mundo visual (OLIVEIRA, L. e MACHADO, 2004).

No tocante a percepção ambiental, esta é expressa pelos moradores por meio da História oral, que segundo Voldman (1996 apud Rodrigues, 2013), é o método que consiste em palavras gravadas, que será compreendida como uma fonte oral. Esse método parte da oralidade das histórias daqueles que a vivenciaram, observaram e que muitas vezes não tem credibilidade no mundo acadêmico, mas que nem por isso, deixam de representar um arquivo vivo das modificações ocorridas nas paisagens ao longo dos tempos passados.

A oralidade vem sendo objeto de estudos de numerosos trabalhos de cunho acadêmico. Trabalhos que tem em comum a interdisciplinaridade, uma vez que a história oral permite o contato e o intercâmbio entre a história e as demais ciências sociais e do comportamento como antropologia, sociologia e a psicologia.

Nesse sentido, a História oral

(...) é antes um espaço de contato e influências interdisciplinares (...) com ênfase nos fenômenos e eventos que permitam, através da oralidade, oferecer interpretações qualitativas de processos histórico-sociais. Para isso, conta com métodos e técnicas precisas, em que a constituição de fontes e arquivos orais desempenha um papel importante. (...) a história oral, ao se interessar pela oralidade, procura destacar e centrar sua análise na visão e versão que dimanam do interior e do mais profundo da experiência dos atores sociais. (LOZANO, 1996)

SANTOS (2001) considera o espaço primeiramente como um "conjunto de fixos e fluxos", os elementos fixos como estradas, pontes, construções, barragens e etc, os fluxos são os movimentos que são condicionados pelas ações. Há uma interação entre os fixos e os fluxos construindo e reconstruindo o espaço, os fixos que produzem fluxos, e este que levam a reprodução de fixos e vice-versa.

De um lado os sistema de objetos condicionam a forma como se dão as ações e, de outro lado, o sistemas de ações leva a criação de objetos novos ou se realiza sobre os objetos préexistentes. É assim que o espaço encontra a sua dinâmica e se transforma (SANTOS, 2001, p $63)$.

Sendo o geoprocessamento uma técnica transdisciplinar, diversas são as ciências que se beneficiam de seu uso através dos trabalhos de localização dos fenômenos e equacionamento e esclarecimento das condições espaciais.

Nesse sentido, conforme apontou Rocha (2000, apud FITZ, 2008, p.24), o Geoprocessamento é:

uma tecnologia transdisciplinar, que, através da axiomática da localização e do processamento de dados geográficos, integra várias disciplinas, equipamentos, programas, processos, entidades, dados, metodologias e pessoas para coleta, 
tratamento, análise e apresentação de informações associadas a mapas digitais georreferenciados.

A percepção da paisagem e a resultante descrição da mesma no discurso do narrador dão evidências para um possível desenvolvimento de um Sistema de Informações Geográficas, cujo banco de dados gerados possa subsidiar a elaboração de mapas temáticos representando os fluxos comerciais dos produtos agrícolas de São João da Ponta no passado.

Conforme Fitz (2008, p.23), o SIG seria definido como

(...) um sistema constituído por um conjunto de programas computacionais, o qual integra dados, equipamentos e pessoas com o objetivo de coletar, armazenar, recuperar, manipular, visualizar e analisar dados espacialmente referenciados a um sistema de coordenadas conhecido.

O fluxograma a seguir representa os procedimentos metodológicos utilizados para elaboração dos mapas resultantes das entrevistas orais.

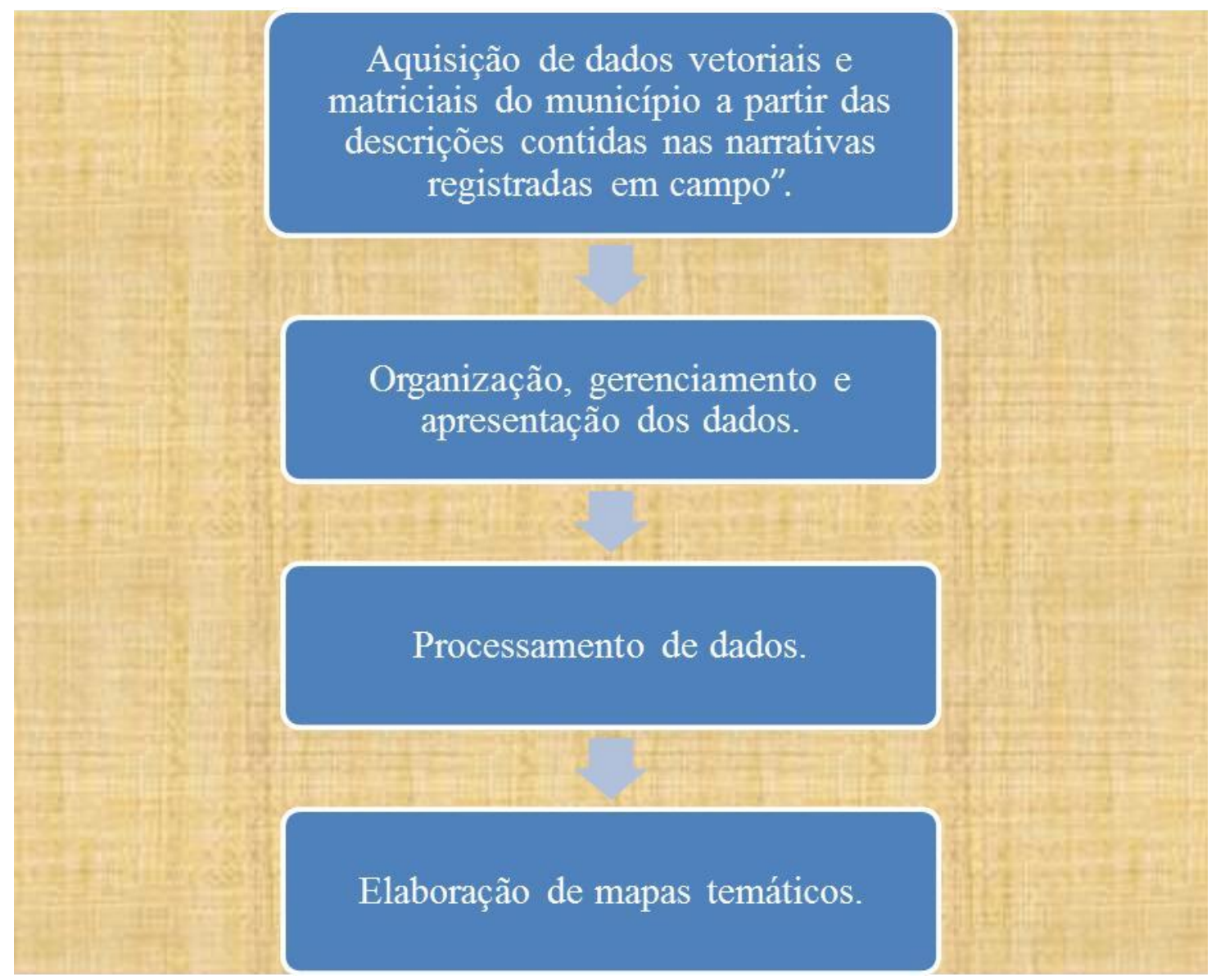

Figura 2 - Fluxograma da metodologia. 


\section{RESULTADOS DAS DISCUSSÕES}

\subsection{ATIVIDADE AGRÍCOLA DE ONTEM: ECONOMIA AGRÍCOLA ESCOADA ATRAVÉS DE RIOS, IGARAPÉS E BAÍA}

No atual município de São João da Ponta, a economia estava baseada principalmente na extração da malva, casca de mangue, maniva, arroz entre outras culturas de subsistência. $\mathrm{Na}$ ausência de registros oficiais que comprovem a quantidade e os fluxos dessa economia no passado, utilizou-se, nesta, pesquisa, a memória da população idosa local através das narrativas orais registradas entre os anos de 2011 a 2012. A seguir será descrito algumas narrativas orais que registram as atividades agrícolas e seus principais fluxos de distribuição anteriores a abertura da rodovia PA-375 na década de 50.

\subsubsection{As principais atividades econômicas no passado: malva, casca de mangue, maniva, arroz, entre outras:}

A gente ia daqui de canoa para vender em São João da Ponta. Vender malva que a gente tirava naquele tempo. Ia ao roçado tirava aqueles feixes de malva, raspava e botava na água. Com 8 dias já ia lavar. Fazia aqueles maços de malva lavada e pegava e ia vender. Chegava lá comprava que tinha que comprar... Tudo isso a gente fazia. Eu ajudava os meus pais a plantar roça. Nós plantava a maniva, nós plantava o arroz, o gergelim. Ajudava o meu pai pelo mangal a bater casca de mangue. Derrubava esses mangueiros que tem no mangal assim e batia e tirava aquela casca. Um bocado de casca! Aí fazia umas rodinhas de cipó, aí a gente enchia. Fazia aqueles feixinhos assim bonitinhos pra levar pro curtume em Belém, que ficava lá no Maguari. Dali saía o couro pra fazer sapato, fazer bolsa, fazer cinto, fazer tudo quanto era coisa. Era feito dessas coisas. Agora não tem mais. (Maria Soares, mulher, 71 anos, 2011).

Eu tirei muito metro de casca de mangue. A gente tinha uma machadinha. Tinha o cabo e a machadinha. Era assim a machadinha [seu Lázaro desenha a machadinha no papel]. O mangueiro, por exemplo, era aqui. Aí, o senhor, tirava uma medida, que era isto aqui, a medida do comprimento do feixe. Aí eu tirava uma medida, e ia embancar [colocar sobre uma bancada] pro senhor, se o senhor fosse o batedor da casca. A gente tirava na semana cinco, seis metros. Era trinta e dois feixes, o metro. Eu trabalhava de segunda a quinta. Quando a maré tava morta. Aí deixava a maré crescer. No período em que a maré tava morta nós saíamos pra várzea pra tirar tala de jacitara, pra fazer umas alcinhas assim [Seu Lázaro faz com as duas mãos a forma de um círculo] umas bolinhas assim. A gente tirava duzentas, trezentas alças... Eram duas alças do feixe. A gente pegava a canoa, tirava tudinho a casca de dentro e botava no teso. Aí a gente ia enfeixar. Enfeixava tudinho e entregava pro cabra que ia comprar casca. Naquela época era mil réis. Aí não tinha outros meios. (...)

Nós não trabalhava mesmo no caranguejo. Nós trabalhava, quando eu tinha 8 anos, trabalhava assim na malva, tirando malva com minha mãe. Era capoeirão, dava muita malva e a gente vendia. Levava lá, pra São João da Ponta. Pra vender lá, daqui pra lá ainda na cabeça. Andando, de bicicleta, de barco... mas de barco era pouco. Mais era andando aí na paulada e gastava três, quatro horas, que era longe. Que não era aí pela estrada! A gente ia, atravessava aqui, ganhava os caminhos. Era tudo pelo caminho! E passava lá o Coqueiro31, descia, varava num rio que chamam Tupuranga, lá na beira da cidade, chegava na casa do Didi, e era lá que nós vendia a nossa malva pra ele. (Lázaro Palheta, homem, 68 anos, 2012). 
Aonde é aquele colégio [Escola Antonia Rosa], ao lado tem a praça, era a casa dele lá, do finado Terto[Santa Rosa]. Ele tinha um comércio grande lá, tinha padaria. Ele comprava [do proprietário local]. E tinha umas mangueiras assim grandes. Ele comprava e aí o pessoal enfeixava [os cascos de mangue] e deixava lá. No outro dia ele botava na canoa já pra levar. Entrava no rio Maguari, que era o curtume lá dentro e aí ia descarregar.

(...)

Tinha um camarada [Terto Santa Rosa] aí, que tinha uma canoa a vela, e ele comprava [malva e outros produtos]. Era os metros, né. A gente fazia aqueles feixezinhos[feixes pequenos] assim e fazia metrado. Aí fazia os metros e vendia o metro. E ele levava por canoa lá pro Maguari. Aquele curtume Maguari, sabe? Ali pro lado de Icoaraci [Distrito de Belém do Pará]. E era lá que eles iam. Tem o rio Maguari mesmo e eles iam bater lá dentro, no curtume. (Raimundo de Moura, homem, 65 anos, 2012).

Como agricultor o senhor Cileno Neves de Lima (89 anos, entrevista oral, 2012), conhecido como seu Quito, plantou arroz, milho, mandioca, feijão, cana, banana, jerimum, melancia e outras coisas mais. A produção era vendida para São Caetano de Odivelas através do porto da comunidade de Porto Grande e dali levada para Castanhal e outros municípios próximos.

Eu conheci este Porto Grande [comunidade] com mais ou menos umas cinco... seis casas. Eu não era daqui. Eu era do Guarumã[atual comunidade de Santa Clara]. O papai era lavrador. Nós tinha roçado. A gente plantava milho, plantava mandioca, plantava o gergelim, plantava a batata e tudo. Plantava e colhia. (Orgarina dos Santos, mulher, 77 anos, 2012).

Como eles faziam, por exemplo, há tempos atrás. Eles pegavam o caranguejo aqui e botavam na canoa daqui e aí iam pra Abaeté [Abaetetuba, município paraense]. Chegavam lá vendiam esses caranguejos em Abaeté e já traziam de lá o tijolo, a telha, a madeira. E como no Marajó era o local que mais vendia farinha, a farinha daqui ia direto pro Marajó. Metiam a canoa aí e iam direto pra lá. Então eles faziam uma troca dessapiramutaba salgada, da capivara, do peixe do mato que é o tamatá e eles levavam daqui e faziam a troca com eles lá. (Raimundo de Moura, homem, 65 anos, 2012).

Sobre essa época, o senhor Raimundo de Moura, recorda e compara a economia agrícola de sua época com a atual e lamenta:

A gente lamenta a agricultura da gente não ter crescimento. Naquela época que a gente tinha mais dificuldade do carro entrar aqui, quando ainda vinha canoa buscar aí no porto! Era arroz, era malva... Hoje, acabou! Acabou a plantação de malva, acabou a plantação de arroz. [Hoje] não tem dificuldades de vim, mas acabou o produto e a gente não pode vender.

\subsubsection{Mapeamento dos principais fluxos de pessoas e produtos agrícolas de São João da Ponta no passado}

Antigamente, antes da construção da estrada PA 375, para sair do atual município de São João

da Ponta, atravessavam-se de embarcação os rios Mocajuba e Mojuim. Eram, basicamente, 
quatro vias de acesso e saída que os moradores das comunidades do município usavam. Eram elas:

Ao norte do rio Mocajuba: saindo da comunidade Deolândia e subindo o rio Desterro, atravessava-se para a vila Murajá, município de Curuçá, e de lá se pegava um carro para Belém e outros lugares.

Ao sul do rio Mocajuba: saindo de São João da Ponta (atual sede municipal), atravessava-se para a vila Lauro Sodré, município de Curuçá, e de lá se pegava um carro para Belém e outros lugares.

Ao norte do rio Mojuim: saindo da comunidade Porto Grande, atravessava-se para a sede municipal do município de São Caetano de Odivelas e de lá se pegava um carro para Belém e outros lugares.

Ao sul do Rio Mojuim: saindo da comunidade Bomfim, atravessava-se para as comunidades de Cotita e Campina, município de São Caetano de Odivelas, de onde se pegava o ônibus que seguia para Vigia e de lá para Belém e demais lugares (RODRIGUES, 2013).

Todo esse perímetro aí não era estrada. Era só caminho e você andava tranquilo, de noite, de dia. Eu cansei de ir daqui [Deolândia] pra Vila Nova e era caminho, andando. A gente atravessa pra ali pra Murajá, pegava o carro e ia embora pro Abade, pra Curuçá e ia embora... São Pedro... pra Belém. Assim... Naquele tempo pra ir a Belém, pra ser mais perto, atravessava de canoa [o rio Mocajuba] pra ali [vila Murajá em Curuçá]. Meu filho cansou de levar a agente pra ali, pra pegar o ônibus às 6 horas da manhã ali no Murajá. Era assim que a gente ia pra Belém. (Maria Soares, mulher, 71 anos, 2011).

Aqui era o seguinte, era caminho. E era assim. De Porto Grande pra São Caetano [sede do município] não fica tão longe. De motor [barco] é trinta minutos. Antes de a gente chegar na estrada de São Caetano com Vigia, tinha uma Campina. A gente pegava o ônibus lá na Campina. Do Bomfim pra Cotita era uma meia hora a remo. Lázaro Palheta, homem, 68 anos, 2012).

Nas páginas seguintes, conforme as figuras 3 e 4 serão representadas cartograficamente as informações dos principais fluxos de pessoas e mais as informações dos principais fluxos de mercadorias do atual município de São João da Ponta. 
Figura 3 - Mapa dos principais fluxos de pessoas

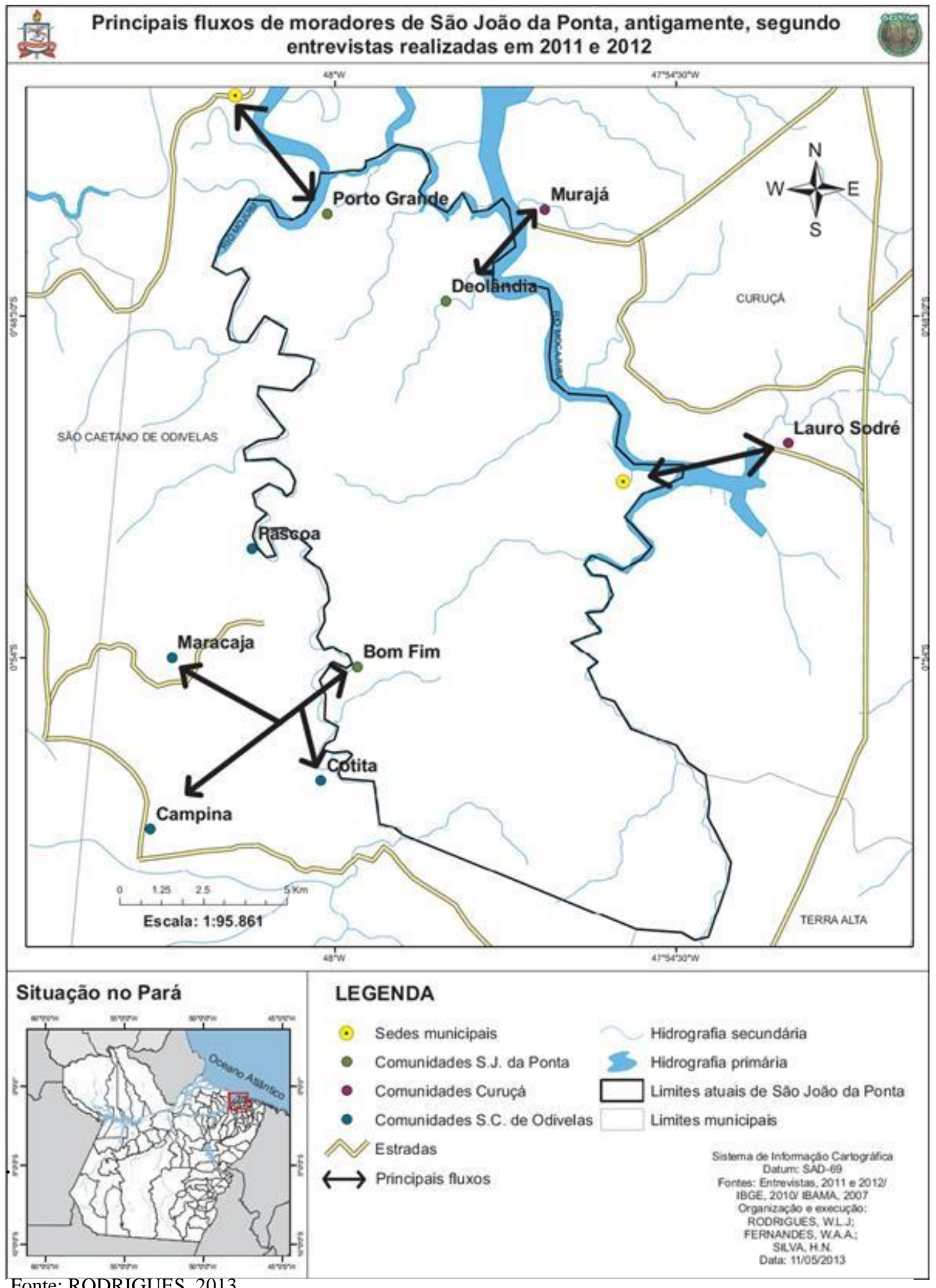

Fonte: RODRIGUES, 2013. 
Figura 4 - Mapa dos principais fluxos de mercadorias.

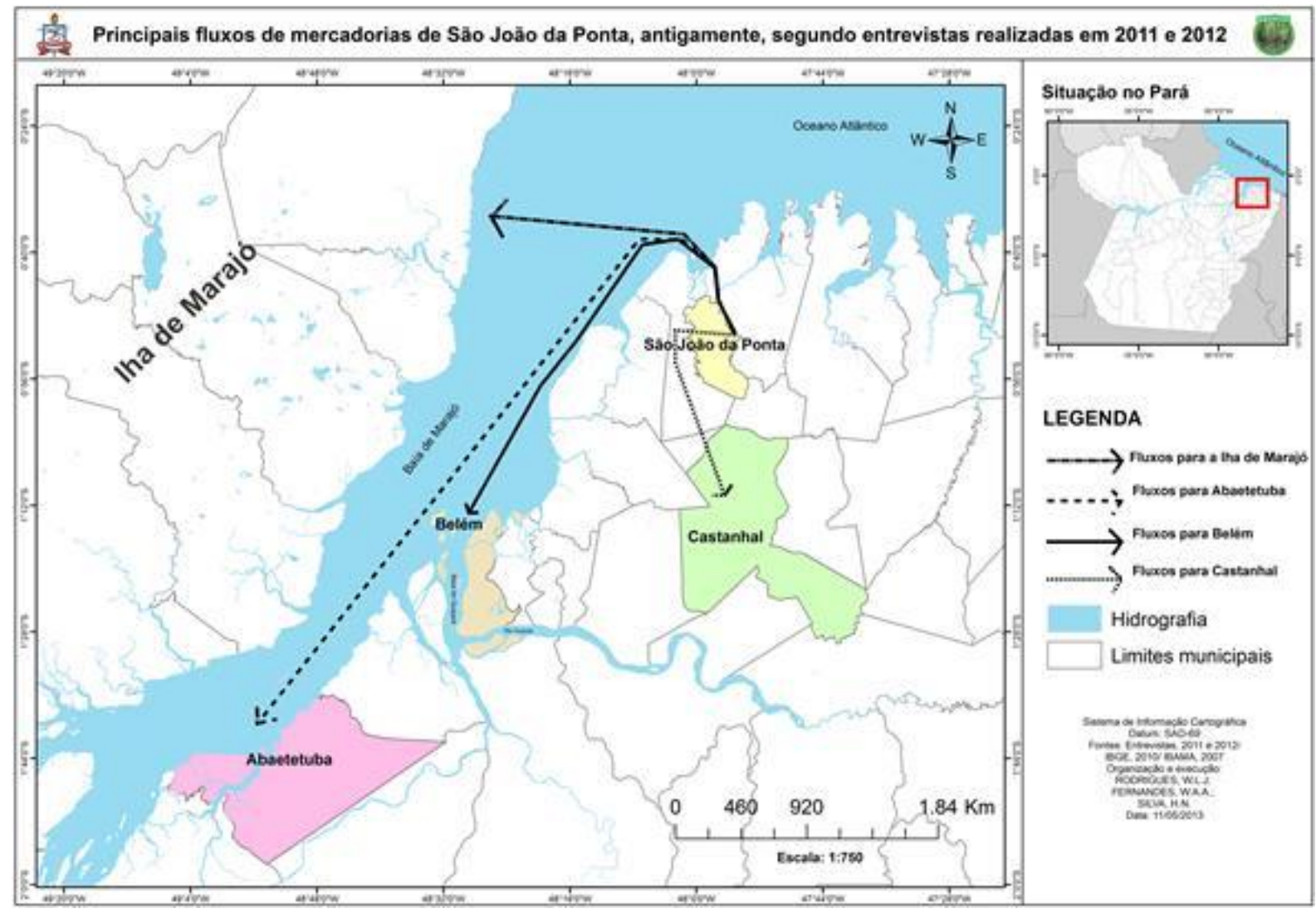

Fonte: RODRIGUES, 2013.

\subsection{Atividade agrícola de hoje: uma economia agrícola baseada na agricultura familiar escoada através da PA-375}

A economia de São João da Ponta está baseada na cata do caranguejo, pesca e agricultura familiar a partir das lavouras temporárias e permanentes.

As maiores produções das lavoras temporárias do município estão nas colheitas do abacaxi (550 mil frutos), arroz (6 tonelads), feijão (90 toneladas), mandioca (9 mil toneladas), melancia (24 toneladas) e milho (21 toneladas). Já as maiores produções das lavouras permanentes estão nas colheitas do coco-da-baía (50 mil frutos), maracujá (72 toneladas) e pimenta-do-reino (24 toneladas) (IBGE, 2010).

A produção é levada pelos próprios agricultores, catadores de caranguejo, pescadores em caminhões, ônibus, carros menores, para serem negociadas diretamente com os consumidores, principalmente nos municípios de Castanhal e Belém, numa viagem que leva em média duas horas para Belém e metade do tempo para Castanhal. Existe também a negociação entre o produtor e os atravessadores. Nesse tipo de negociação, o pequeno produtor, sente-se obrigado a vender seus produtos por preços bem abaixo do mercado 
deixando de ganhar mais se fosse vender seu produto diretamente com o consumidor sem a intermediação do atravessador.

Sobre a relação entre o catador de caranguejo e o atravessador (que nos versos aparece como "patrão"), o senhor Lázaro Favacho da Costa compôs a seguinte letra de Carimbó:

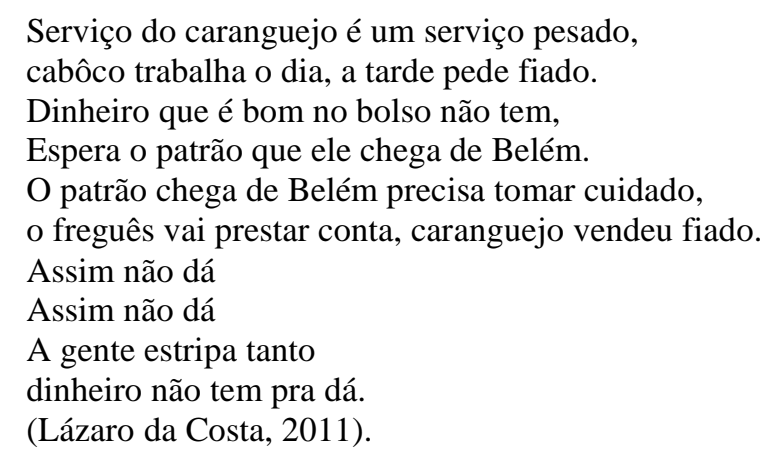

Figura 5 - Mapa dos principais fluxos de mercadorias e pessoas na atualidade.

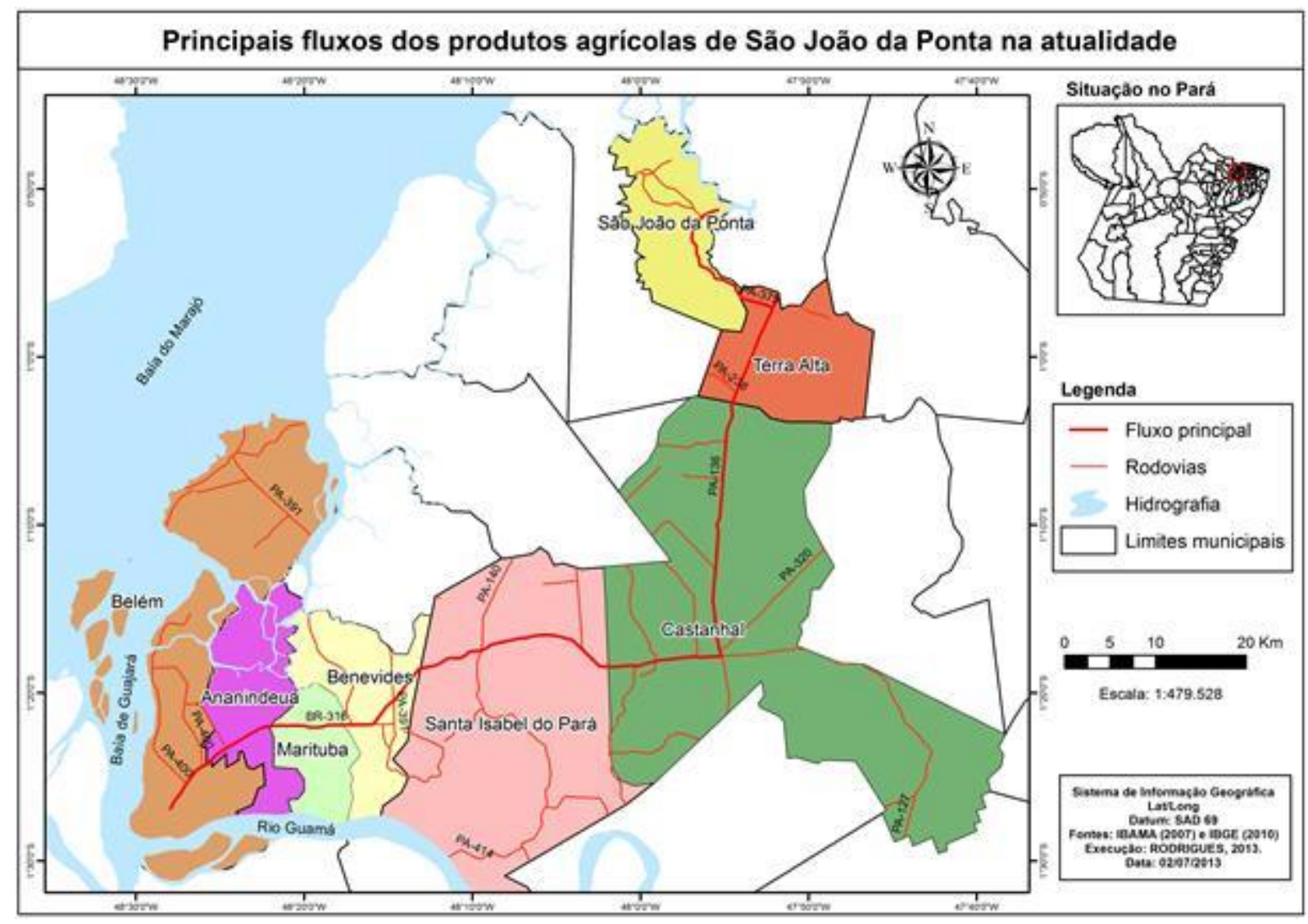

Fonte: RODRIGUES, 2013.

Para proteger e preservar as áreas de mangue, de onde vem grande parte da produção do município, a pedido dos próprios moradores, foi dado início ao processo de criação da Reserva Extrativista Marinha de São João da Ponta.

A Reserva Extrativista de São João da Ponta foi criada por meio do Decreto $\mathrm{S} / \mathrm{N}$ de 13 de dezembro de 2002, abrangendo uma área de aproximadamente 3.203,24 ha (três mil, duzentos 
e três hectares e vinte e quatro centiares) e um perímetro aproximado de 5. 268,88 m (cento e trinta e um mil, duzentos e sessenta e oito metros e oitenta e oito centímetros). Possuindo na sua dominialidade territorial, a predominância do ecossistema de manguezal. Este ecossistema, segundo a Lei 4.771/65 (Código Florestal), representa áreas de preservação permanente (APP), não edificante. As comunidades usuárias moram no entorno, nas áreas de terra firme. Para essas comunidades, a unidade de conservação representa uma grande área de produção (RODRIGUES, 2013).

Figura 6 - Reserva Extrativista Marinha de São João da Ponta.

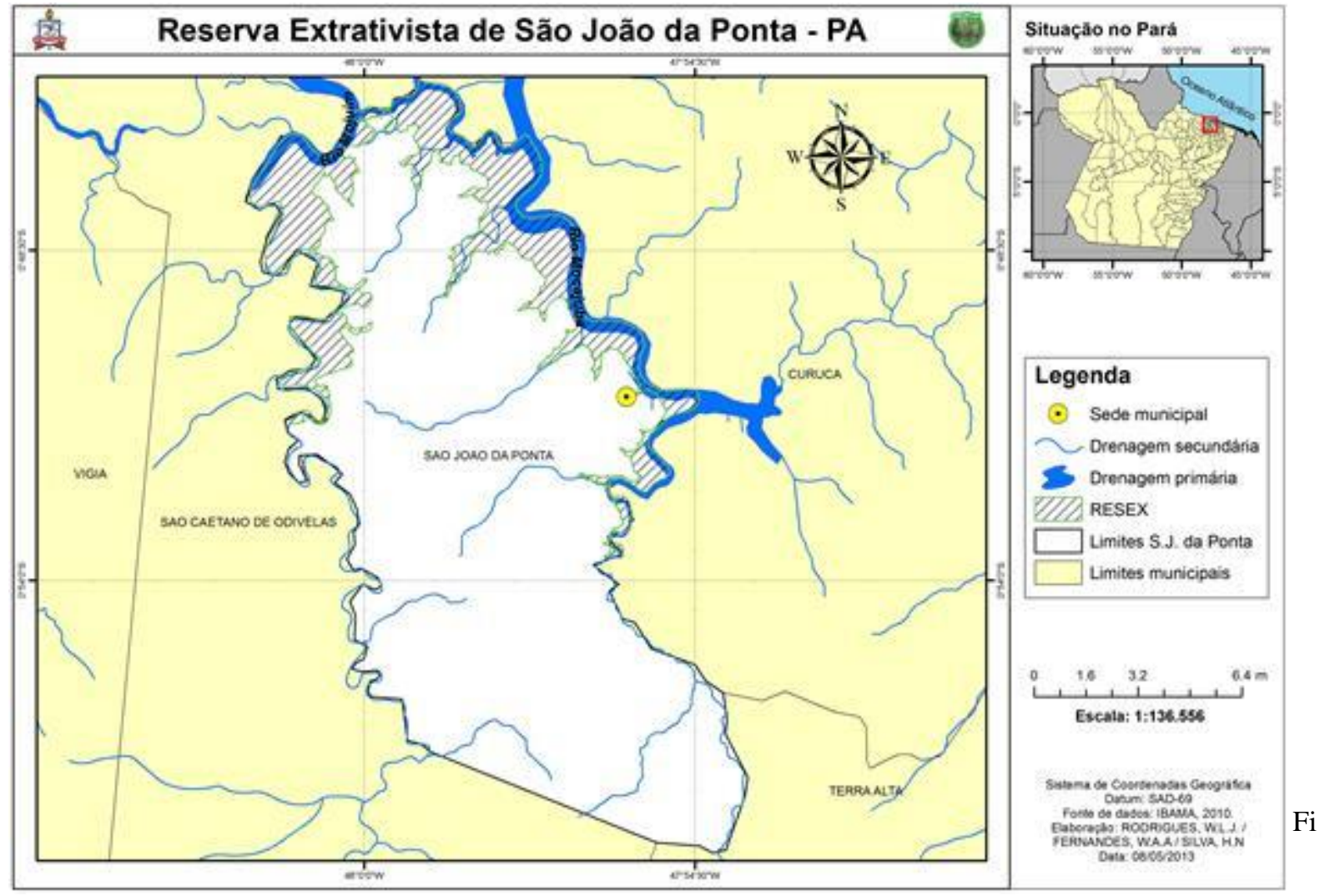

Fonte: Rodrigues, 2013.

Então o que seria uma RESEX?

As Resex são unidades de conservação de uso sustentável que tem como objetivo proteger os meios de vida e a cultura de suas populações extrativistas tradicionais e assegurar o uso sustentável dos recursos naturais da unidade (Lei 9.985/2000 - SNUC).

Sobre a importância da criação da RESEX para preservação das áreas de mangues o senhor João Roberto da Silva nos fala o seguinte:

A criação da RESEX pra nós foi muito bom. Pra alguns, não. Porque quando começamos aqui na criação da RESEX aí diziam que iam proibir a pesca, a RESEX ia proibir pegar caranguejo, que eles não iam poder mais pescar é... nós fomos taxados aqui de, de... de assim de uma forma de trazer uma coisa pra cá que ia proibir um bocado de coisas. Na verdade, ela não proibiu. O que a RESEX faz? Nós hoje... eu como agente ambiental voluntário, a gente trabalha em 
cima da preservação. Se você preservar, seus filhos, nossos filhos vão ter mais tarde e nossos netos até nossos bisnetos. (João Roberto da Silva, 2011).

A estrada a qual os moradores se referem em relatos é a Rodovia PA - 375, a qual se baseia no Programa de reabilitação e pavimentação de rodovias, cujos objetivos era fazer a integração das sedes dos principais municípios do Estado do Pará aos sistemas rodoviários estaduais e federais. Entre esses objetivos estavam também: o provimento do desenvolvimento regional da agropecuária, do turismo e da mineração do Estado. "Atendendo desta maneira à demanda econômica atual e induzindo um crescimento sustentável com inclusão social”. (Relatório de Controle Ambiental - RCA, 2009, p. 8)

A rodovia encontra-se, no km-39 da PA-136, nos limites administrativos do município de Terra Alta, com a PA-375, que se estende por 18,2 km até a Sede do município de São João da Ponta às margens do Rio Mocajuba. Conforme Gonçalves (2012), as obras de pavimentação da PA-375 ocorrem desde 2010, fato que demonstra causar impactos ambientais aos cursos d’água que são entrecortados por ela, expressos na figura 7 .

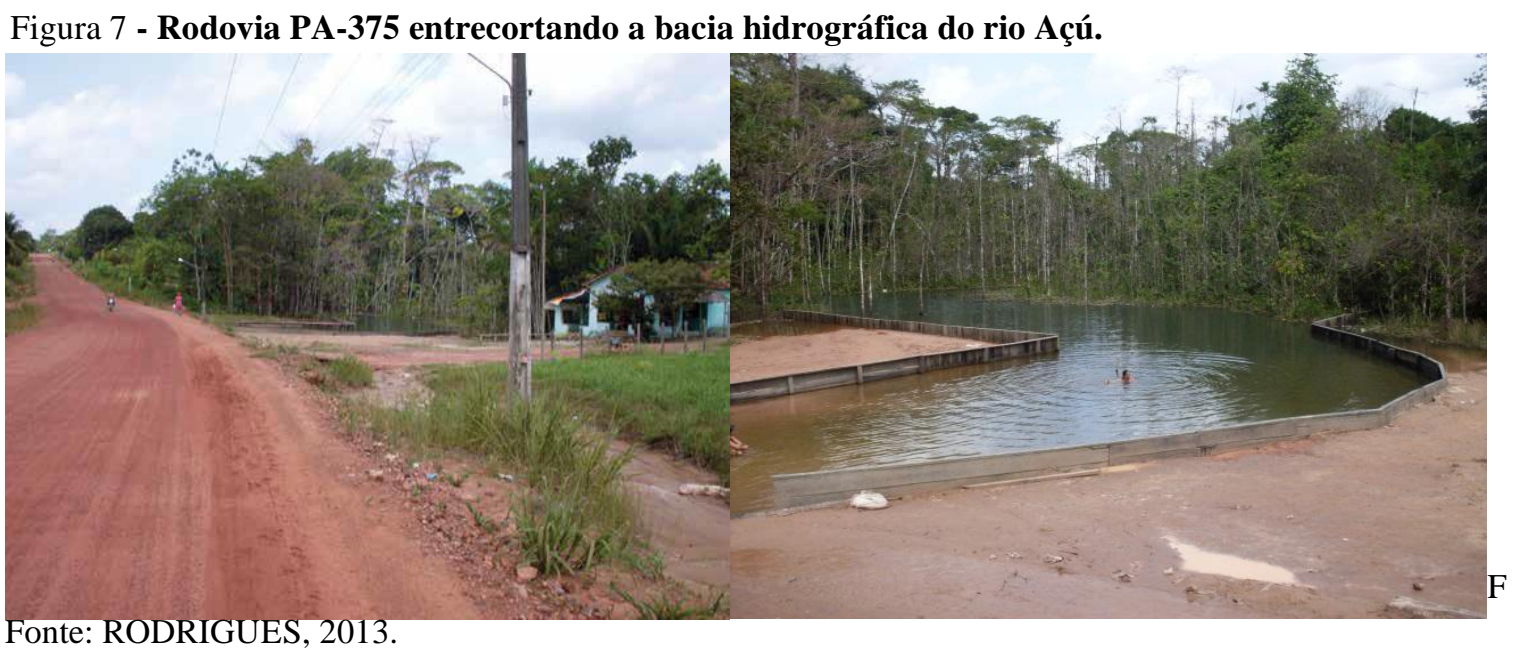

\section{CONSIDERAÇÕES FINAIS}

O perfil de construção histórica de incontáveis cidades amazônicas conta com a utilização de seus recursos hídricos, não apenas de seus elementos vivos, mas do próprio curso hídrico enquanto recurso necessário ao transporte de pessoas e escoamento de suas produções para outras cidades. Fato em grande parte alterado em decorrência da criação dos novos acessos criados a partir do Plano Nacional de Integração - PIN, por volta da década de 1950, o qual foi criado a partir do ideário de necessidade de integração da Amazônia ao restante do 
território brasileiro, e logo, a forma implantada a partir daquele momento viria a ser a construção das estradas e rodovias. Esse novo elemento inserido no processo socioeconômico dessa região viria a facilitar não só a ligação com todo território, mas também o aumento da velocidade da circulação da produção.

O que não foi alvo de destaque em meio a inserção desse novo elemento na dinâmica de circulação amazônica foram justamente as consequências socioambientais que viriam ao longo da chegada da modernidade, uma vez que para se alcançar o âmbito da modernidade necessariamente, tem-se que impingir mudanças no ambiente e, diga-se de passagem, inúmeras são feitas sem planejamento prévio, que leve em consideração os elementos tanto ditos da natureza, como os culturais, no entanto, o que se nota, é que as comunidades, especialmente as que ainda mantêm determinados hábitos culturais herdados dos mais antigos, ainda se preocupam substancialmente com o destino de seus descendentes, quando percebem que os elementos culturais de suas terras já não tem a mesma qualidade e quantidade de outrora, quando dava para sustentar numerosas famílias durante muitas gerações.

\section{REFERÊNCIAS}

IBGE, Produção da Extração Vegetal e da Silvicultura 2010. Rio de Janeiro: IBGE, 2011.

IBGE, Produção Agrícola Municipal 2010. Rio de Janeiro: IBGE, 2011.

SANTOS, Milton. A natureza do espaço: técnica e tempo, razão e emoção. $-4^{\text {a }}$ ed. $4^{\text {a }}$ reimpressão. - São Paulo: Editora da Universidade de São Paulo, 2008.

RODRIGUES, W.L.J.; FERNANDES, W.A.A.; PIMENTEL, M.A.S. Memórias de São João da Ponta a partir de narrativas orais: identificação e (re)construção da identidade social. In: ENCONTRO DA REDE DE ESTUDOS RURAIS - V, 2012. Belém, Pará, Brasil. Anais 2012.8 p.

RODRIGUES, W.L.J. Memórias de São João da Ponta a partir de narrativas orais. $1^{\text {a }}$ ed. - Belém: GEPPAM/UFPA, 2013. 208p.

BOTELHO, R. G. M. e SILVA, A. S. Bacia hidrográfica e a qualidade ambiental In.: (Org.) VITTE, A. C. e GUERRA, A. J. T. Reflexões sobre a geografia física no Brasil. Rio de Janeiro: Bertrand Brasil, 2004. 180 p.

GONÇALVES, A. C. O. da. Desenvolvimento territorial em unidades de conservação : o caso da RESEX marinha de São João da Ponta - PA. 2012. 119 p. Dissertação (Mestrado em geografia) - Programa de Pós- graduação em geografia - UFPA, Pará, 2012.

OLIVEIRA, L. e MACHADO, L. M. C. P. Percepção, cognição, dimensão ambiental e desenvolvimento com sustentabilidade. In.: (Org.) VITTE, A. C. e GUERRA, A. J. T. Reflexões sobre a geografia física no Brasil. Rio de Janeiro: Bertrand Brasil, 2004. 180 p. 
GOVERNO DO PARÁ. Melhoria e pavimentação da rodovia PA-375. Relatório de Controle Ambiental. Secretaria de Estado de Transportes: Bit Engenharia, 2009. p. 162

LOZANO, J.E.A. Prática e estilos de pesquisa na história oral contemporânea. In: Uso \& Abusos da História Oral. Org. Marieta de Moraes Ferreira e Janaína Amado, 2005.

FITZ, P.R. Geoprocessamento sem complicação. São Paulo: Oficina de Textos, 2008, p.161. 